Journal of Accident and Emergency Medicine 1994 11, 109-111

\title{
Paediatric road accidents in two health districts
}

\author{
R.S. MOORE, ${ }^{1}$ C.L. SUMMERS, ${ }^{1}$ M. JACKSON ${ }^{2}$ and B. TESFAYOHANNES ${ }^{3}$
}

${ }^{1}$ Department of Accident and Emergency Medicine, Royal Liverpool Children's Hospital, Liverpool ${ }^{2}$ Institute of Child Health, Royal Liverpool Children's Hospital, Liverpool and ${ }^{3}$ Department of Accident and Emergency Medicine, Countess of Chester Hospital, Chester

\section{SUMMARY}

For a 1-year period from 1 January 1990 all children seen, as a result of road traffic accidents (RTAs), in two accident and emergency departments (A\&E), one in Liverpool and one in Chester were studied. Simple data were collected and injury severity scores (ISS) were used to assess injuries. Progress was monitored at 3 months post-injury by a review of hospital case notes.

A total of 710 children fulfilled the study criteria in the year with a male:female ratio of $1.7: 1$. Only $37 \%$ of children were accompanied by an adult at the time of their accident. Overall $29 \%$ of children in vehicles were restrained and only three of 75 cyclists wore cycle helmets. Most injuries were minor with ISS of less than 9 in $96 \%$ of cases. Two children died after admission as a result of severe head injuries.

The results were similar to those from other centres but highlight a need for continuing public education on child supervision, safe driving habits and the need for environmental changes.

Key words: children, morbidity, mortality, road traffic accidents, urban environment

\section{INTRODUCTION}

In 1988, RTAs accounted for 267 childhood deaths, produced 5204 serious injuries and were the reason for 14842 A\&E attendances in the UK by the paediatric population. ${ }^{7}$ These figures translate to a small number of deaths in each Health District but a large morbidity level. This study set out to examine the incidence of children's road accidents in two Health Districts in Mersey Region and to determine whether there were any differences between the two districts. ISS $1990^{2}$ was used to compare the injuries sustained. Although this is not a specific scoring system for children it is internationally known and easily reproducible.

\section{SUBJECTS AND METHODS}

Information concerning children attending the A\&E departments at the Royal Liverpool Children's Hospital (RLCH) and the Countess of Chester Hospital ( $\mathrm{COCH}$ ) was collected over a 12-month period commencing 1 January 1990. Details of the accident were recorded by the doctor at the time of attendance and included the age and sex of the patient, the date and time of the accident and whether an adult ( 16 years and over) was supervising the child at the time of the incident. Attendances were divided into road user groups: pedestrians, cyclists and vehicle occupants front or rear. A record was made of the injuries sustained and of whether the child was admitted. These details were updated 3 months later from a search of the hospital case notes.

Each child's injuries were assessed by ISS. For those who were admitted the duration of in-patient treatment was recorded. The number of returns to out-patient clinics or A\&E departments was noted for those not admitted.

The data were analysed to compare trends and patterns in the two districts. Data were subjected to simple analysis and the calculation of mean and range where appropriate. Hypotheses regarding significant differences between the two hospitals were investigated using the Wilcoxon Rank Sum test and chi-square test for continuous and noncontinuous variables respectively.

\section{RESULTS}

Table 1 summarizes the results. During 1990 A\&E at $\mathrm{RLCH}$ treated 52061 patients from a catchment population of 227954 children. (In Liverpool there are three other A\&E departments, but RLCH sees the majority of children in the district.) The $\mathrm{COCH}$ treated 11291 patients under the age of 16 years in 1990, from a catchment population of 32757 chil- 
R.S. Moore et al.

Table 1. Results of the study

\begin{tabular}{llll}
\hline & \multicolumn{1}{c}{$\mathrm{COCH}$} & \multicolumn{1}{c}{ RLCH } & \multicolumn{1}{c}{$P$} \\
\hline $\begin{array}{l}\text { Incidence } \\
\begin{array}{c}\text { Pedestrian } \\
\text { (with adult) }\end{array}\end{array}$ & $61 / 32,757$ & $649 / 227,954$ & $<0.005$ \\
$\begin{array}{c}\text { Pedestrian } \\
\text { (unaccompanied) }\end{array}$ & $26 / 32$ & $352 / 415$ & n.s. \\
$\begin{array}{c}\text { Cyclists } \\
\begin{array}{l}\text { Vehicle } \\
\text { (occupants } \\
\text { restrained) }\end{array}\end{array}$ & $9 / 17(53 \%)$ & $42 / 165(26 \%)$ & $P<0.005$ \\
$\begin{array}{l}\text { Vehicle } \\
\text { (occupants } \\
\text { unrestrained) }\end{array}$ & $8 / 17(47 \%)$ & $123 / 165(74 \%)$ & $P<0.005$ \\
\hline
\end{tabular}

dren. Of the paediatric patients treated at $\mathrm{RLCH}$, 649 were the result of RTAs and 61 patients fell into this category at $\mathrm{COCH}$. This case load represented under $2 \%$ of the paediatric work load at each department. The level of RTAs in Liverpool gave an inci-
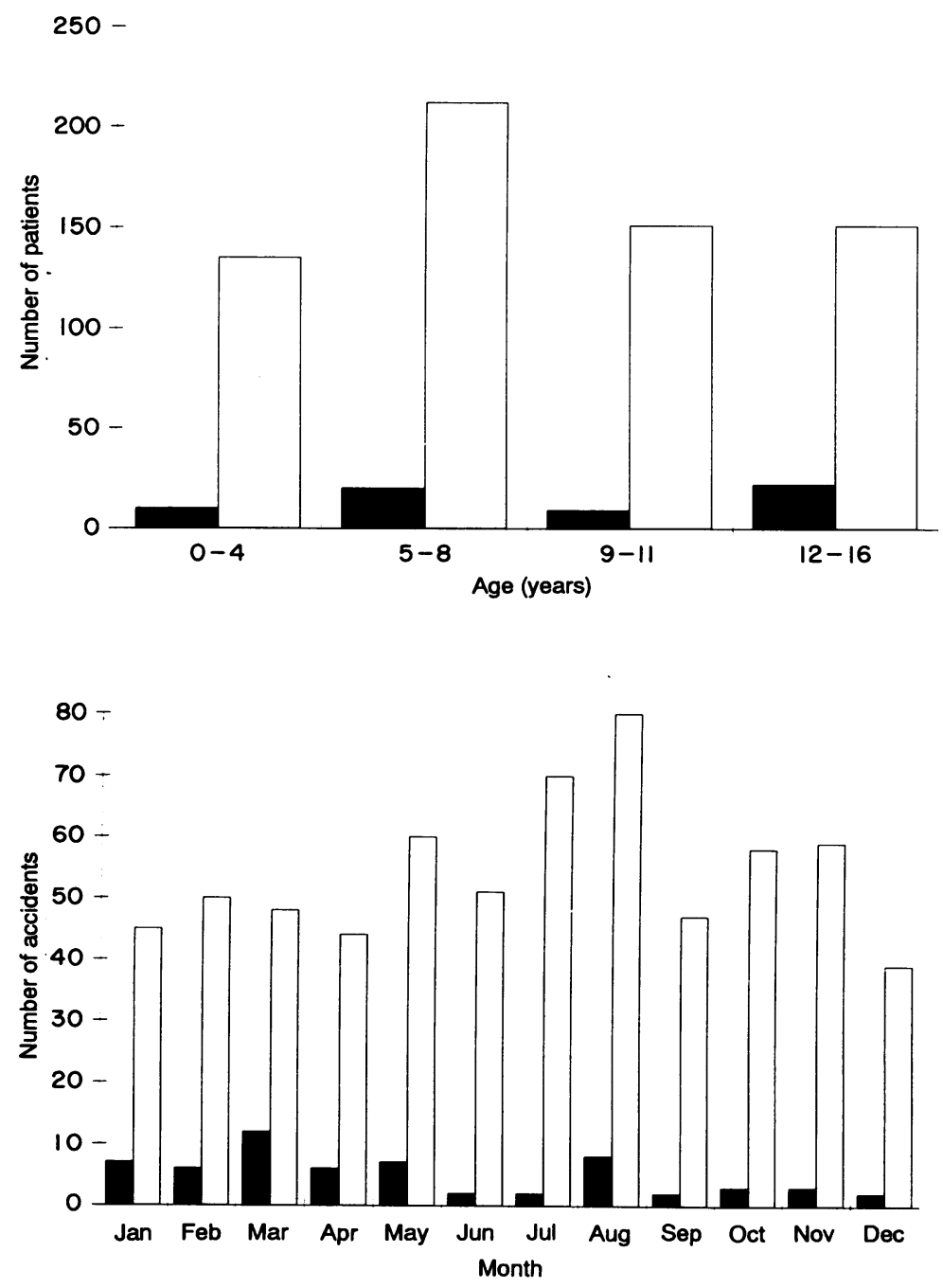

Fig. 1. Age of patients seen after RTAs ( $\mathbf{\square}, \mathrm{COCH}$; $\square \mathrm{RLCH})$.

Fig. 2. Incidence of RTAs in 1990 ( $\mathrm{a}, \mathrm{COCH}$; $\square \mathrm{RLCH})$. dence of $2.85 \%$ per 1000 children and in Chester the incidence was $1.86 \%$ per 1000 children. This is a significant difference of $P<0.005$.

The age distribution of the patients seen at each hospital is shown in Fig. 1. The male:female ratio was 1.7:1 for all types of accident. One hundred and sixty-seven children (22\%) were admitted, however, $71 \%$ of those admitted were fit for discharge as inpatients after up to 3 days. The mean length of stay was 2 days, the range being 1-81 days. Eighty-six others attended out-patient clinics or the A\&E department for further treatment. The majority required only one return visit reflecting the minor nature of their injuries. At RLCH the peak of accidents was seen during the summer but this was not reflected so markedly at $\mathrm{COCH}$ (Fig. 2). Accidents were more common in the afternoon in both areas, with smaller peaks at 12.00 and $09.00 \mathrm{~h}$.

The majority of the children $(62.15 \%)$ were pedestrians at the time of their accident. The mean ISS of children who were unaccompanied pedestrians 
Paediatric road accidents was 3.2 with a range of $0-41$. The higher end of the range represented the death of a child. Another child who died was also an unaccompanied pedestrian and had an ISS of 19. Both these children had severe head injuries. For those children who were accompanied by an adult at the time of their incident the mean ISS was 2.5 with a range of 0-29. However, most children suffered minor cuts and bruises with an ISS of less than 3.

Only three of the 75 cyclists $(10.95 \%$ of the total) were wearing a cycle helmet at the time of their accident. The mean ISS of all the cyclists was 1.72 , with a range of $0-14$. No children died during the study period as a result of a cycling accident.

One hundred and ninety-three children $(27.26 \%$ of the total) were motor vehicle passengers at the time of their accident, the majority riding in the rear. Overall, $29 \%$ of patients were restrained.

\section{DISCUSSION}

RTAs account for a small proportion of the paediatric work load at each of the hospitals in the study. However, accidents occur in healthy children with a predicted normal life span and their prevention is therefore of great importance. Although the social class of each child was not determined, the overall deprivation in Liverpool compared with Chester, using the Office of Population Censuses and Surveys statistics, support many studies regarding the higher incidence of RTAs in under-privileged areas. $^{3.4}$ Prevention of accidents requires modification of children's play areas, as well as a change in the road users' behaviour. ${ }^{5}$ The redesigning of urban environments, as already in progress in Scandinavia and the Netherlands, would help to prevent accidents. ${ }^{6}$

Head injury remains the most common cause of death for pedestrians. ${ }^{7}$ The poor compliance with cycle helmet wearing is gradually being reversed and there is strong evidence to suggest that protecting the head prevents head injury, at least in those who have simple accidents that do not involve another vehicle. ${ }^{8}$

The legislation of 1983 to enforce the compulsory wearing of front seat-belts means that the national average for compliance is now $91 \%$. This study demonstrates a rate of seat-belt wearing of $79.4 \%$. However, despite the legislation which came into force in July 1991 to enforce the compulsory wearing of rear seat-belts where fitted, ${ }^{10}$ under $20 \%$ of the study population were restrained whilst travelling in the rear of a motor vehicle. This is despite national surveys prior to the study that questioned the general public and found support for the wearing of front and rear restraints, ${ }^{11}$ which has been shown to substantially reduce the incidence of injury to both front and rear passengers. ${ }^{10}$

This study has highlighted the continuing morbidity and mortality from RTAs in two Health Districts within one Region. The results do not differ from other national studies, ${ }^{12}$ but serve to reinforce the need for local and national measures to improve both the environment for child pedestrians and their protection when cycling or travelling in vehicles to reduce their morbidity and mortality.

\section{REFERENCES}

1. Child Accident Prevention Trust (1991) Factsheet, July. CAPT, London.

2. Yates D.W. (1990) Scoring systems for trauma. British Medical Journal 310, 1090-1094.

3. Sunderland R. (1984) Dying young in traffic. Archives of Disease in Childhood 59, 754-757.

4. Sharples P.M., Storey A., Ansley-Green A. \& Eyre J.A. (1990) Causes of fatal childhood accidents involving head injury in Northern Region 1979-1986. British Medical Journal 301, 1193-1198.

5. Editorial (1991) Political headlines. British Medical Journal 302, 68.

6. Avery J.G. \& Avery P.J. Scandinavian and Dutch lessons in childhood road traffic accident prevention. British Medical Journal 285, 621-626.

7. Atkins R.M., Turner W.H., Duthie R.B. \& Wilde B.R. (1988) Injuries to pedestrians in road traffic accidents. British Medical Journal 297, 1431-1434.

8. Thompson R.S., Rivara S.P. \& Thompson D.C. (1989) A case controlled study of the effectiveness of bicycle safety helmets. New England Journal of Medicine 320-1367.

9. Bodiwala G.G., Thomas P.D. \& Otubushin A. (1989) Protective effect of rear restraints during car collisions. The Lancet $\mathbf{i}, 369-371$.

10. Editorial (1990) Back set passengers on both sides of the channel told to belt up. British Medical Journal 301, 1352.

11. Yates D.W. (1989) Rear seat belts should be encouraged by a mixture of legislation and incentives. British Medical Journal 299, 341-342.

12. Keeling J.W., Golding J. \& Miller H.K.G.R. (1985) Non-natural deaths in two health districts Archives of Disease in Childhood 60, 525-529. 